\title{
Patience and Vaccination
}

Ho Fai Chan ${ }^{1,2}$, Stephanie M. Rizio ${ }^{3,4}$, Ahmed Skali³, and Benno Torgler ${ }^{1,2,5^{*}}$

November 2021

\begin{abstract}
Vaccination against COVID-19 and other diseases is a pressing public health issue. We hypothesize that a short-term orientation (impatience) - as it heavily discounts the future benefits of actions taken today - leads to lower rates of vaccination. Using a recently constructed, experimentally validated measure of patience, we document four results consistent with our hypothesis. First, patience alone explains a large share (21\%) of the global variation in COVID-19 vaccinations across countries as of November 2021 (Study 1a; N = 76). An increase in patience of one S.D. is associated with 12 p.p. larger vaccination rates. Second, using duration models (Study $1 \mathrm{~b} ; 4,180 \leq \mathrm{N} \leq 9,973)$, we demonstrate that more patient countries are quicker to reach high COVID-19 vaccination thresholds. Third, our results are not specific to the COVID-19 pandemic: in Study 2a, we show that beliefs regarding the safety and effectiveness of vaccination against swine influenza (H1N1) in 2009 are also well-explained by patience in a sample of sub-national regions of Europe $\left(\mathrm{N}_{\text {regions }}=138 ; \mathrm{N}_{\text {countries }}=17\right)$. Fourth, in Study $2 \mathrm{~b}$, we show that our results are not specific to pandemics: patience also explains the global variation in infant vaccinations against 12 common diseases $(\mathrm{N}=75)$.
\end{abstract}

Keywords: long-term orientation; vaccination; COVID-19; patience; time preferences

\footnotetext{
${ }^{1}$ Centre for Behavioural Economics, Society and Technology (BEST).

${ }^{2}$ Queensland University of Technology.

${ }^{3}$ University of Groningen.

${ }^{4}$ University of Melbourne.

${ }^{5}$ Center for Research in Economics, Management, and the Arts (CREMA).

* For helpful comments and suggestions thanks are due to Brown Bag Seminar participants at Queensland University of Technology.
} 


\section{Introduction}

At the time of writing, global vaccination rates against COVID- $19^{1}$ are still far from the levels necessary to attain the herd immunity threshold ${ }^{2}$, which most studies place at around 60 to $70 \%$ (Aschwanden 2020). High vaccination rates are crucial for a return to normal life, with familiar levels of social contact, work, education, travel, and economic activity, as emphasized by the World Health Organization, International Monetary Fund, ${ }^{3}$ and many other national and international organizations. At the same time, vaccine hesitancy is a global problem (Solís Arce et al. 2021) standing in the way of a return to normalcy. Such sentiment is not a completely new phenomenon; for example, Europe and the United States had large antivaccination movements in the $19^{\text {th }}$ century and the topic of vaccination was linked to some of the most controversial debates of the era (Snowden 2019). Satirical cartoons showed societal anxieties (see SI Figure A1). Charles Dickens' frustration about slow vaccination uptake led him to write Bleak House. Waves of discussions around vaccination and antivaccination over the last two centuries are reported in SI Figure A2, as measured by Google Books (British and English books). Understanding why people do or do not vaccinate is therefore not only crucial for the COVID-19 situation that we are facing now, but also for any future pandemic.

The decision to get vaccinated is one that each individual has to make for themselves (notwithstanding vaccine mandates, which we do account for). The vaccination decision is of course influenced by many factors, including the vaccination status of others (Ibuka et al. 2014), but ultimately, it is incumbent upon each individual to decide according to her own preferences. In this paper, we study the association between patience and vaccination in four studies. Specifically, we hypothesize that patience leads to more positive attitudes towards vaccination and higher vaccination rates. Patience, or the ability to delay rewards, has been of interest to social and behavioural scientists for decades, if not centuries (Rae 1834, Klineberg 1968; Davids 1969; Mischel and Ebbesen 1970; Triandis et al. 1973; Frederick et al. 2002; Stevens et al. 2005; Rosati et al. 2007). Our argument is that vaccination should increase with patience because vaccines have long-term benefits (Antia et al. 2018; Nichol et al. 2007); at the same time, vaccines offer no obvious short-term benefits (as immunity is not instantaneous), ${ }^{4}$ and can even entail short-term costs, both in terms of inconvenience and in the shape of disease-like symptoms immediately after

\footnotetext{
${ }^{1}$ For current updates, see Covid-19 vaccine tracker (ft.com).

2 The threshold is subject to variations depending on epidemiological and immunological factors in the form of population structure, variations in transmission dynamics between populations, and immunity waning (Randolph and Barriero 2020).

${ }^{3}$ World Health Organization: COVID-19 Vaccines; Wall Street Journal: Vaccination Rates Drive Global Economic Growth Prospects, IMF Says.

${ }^{4}$ For example, antibodies against smallpox begin to be produced about a week after vaccination. COVID-19 vaccines are generally effective two weeks after inoculation, see Center for Disease Control and Prevention.
} 
vaccination. As such, we argue that impatient people are less likely to view vaccination favourably or to seek vaccination, as a result of heavily discounting the future benefits of vaccination. Patience leads to more investment into future rewards, and matters because the investment is made today even though the benefit may not be felt today. As Sunde et al. (2021) show, patience leads to more human and physical capital accumulation, both of which entail costs now but benefits later. Here, we find that patience predicts attitudes towards vaccination as well as actual vaccination.

Of course, patience is not the only decision-making parameter which can influence one's stance towards vaccinating; attitudes towards risk (the future is uncertain) and cooperation (my decision to vaccinate affects others) are key competing explanations. We comprehensively control for risk tolerance and social preferences, including positive and negative reciprocity, altruism, and trust. Risk and social preferences do not explain away the importance of patience; in fact, none of these other decision-making parameters is as robustly correlated with vaccination as patience, and none explains as much of the variation as does patience.

In summary, our results show that patience explains a large share of the global variation in COVID-19 vaccinations (Study 1a) and that more patient countries are quicker to reach high levels of vaccination (Study 1b). In Study 2a, we examine whether the results from Study 1 are specific to the COVID-19 pandemics; we find that they are not, as patience predicts attitudes towards vaccination against the H1N1 swine influenza in a cross-section of European regions. In Study 2b, we ask whether the results are peculiar only to pandemics: instead, we find that patience also predicts the global variation in 'business-as-usual' infant vaccinations. Our results thus point to a large role of patience in explaining actual vaccinations and attitudes towards vaccines.

Our results align well with Fehr and Leibbrandt (2011), Curry et al. (2008), and Espín et al. (2012), who show that patient people are more cooperative. This is important if one views vaccination as a cooperative endeavour since one's decision to vaccinate has effects on others and affects their own decision to vaccinate (Korn et al. 2020). But appeals to prosociality (or the common good) are found to have no effect on COVID-19-related health behaviours (Rabb et al. 2021), despite the public good nature of vaccination (see also the reply by Korn et al. 2021). Scholars have also cast doubt on whether prosociality matters at all for cooperation (BurtonChellew and West 2013). This brings into question whether social preferences are relevant targets for interventions aiming to encourage vaccination, which remain the only way forward towards a return to normalcy. Our results suggest that patience is markedly more important than risk and social preferences and is not explained away by those preferences; as such, we argue that appeals to patience should be investigated as a way to promote vaccination. 
Our measures of patience, risk, and social preferences come from the Global Preferences Survey (GPS; Falk et al. 2018). The GPS used experimentally validated survey questions to measure time, risk, and social preferences; the survey responses in the GPS reflect how people behave in incentivized experiments, such that the GPS measures largely mitigate desirability bias and other common issues which may affect the interpretability of survey responses. The GPS was fielded in 76 countries through the infrastructure of the Gallup World Poll and collected data on nationally representative samples of at least 900 individuals per country (with the exceptions of Haiti and Suriname, which have small populations, where $\mathrm{N}=500$ approximately), for a total of approximately 80,000 respondents worldwide. Countries at various levels of development from all continents were sampled (SI Table B1), thus avoiding the common issue of performing research using data exclusively from WEIRD cultures (Western, Educated, Industrialized, Rich, Democratic; Henrich et al. 2010, Henrich 2021). The countries sampled in the GPS include approximately $87 \%$ of the world's population ( 6.6 out of 7.6 billion people).

In the GPS, patience was measured through ( $($ ) hypothetical choice tasks, administered using the staircase method, where the respondent decides between a given payment today or a larger payment in a year's time, and (iv) a question asking, on a scale of 0 to 10 , "How willing are you to give up something that is beneficial for you today in order to benefit more from that in the future?". The final measure of patience is calculated by combining (i) and (ii) using weights observed in incentivized laboratory experiments (Falk et al. 2016, 2018).

\section{Study 1a results: patience and global vaccination rates against COVID-19 in October-} November 2021

Figure 1 displays the global correlation between the percentage of the population vaccinated with at least one dose, which we use as our proxy for the vaccination rate, and patience, as of the latest available vaccination rate for each country, all of which fall in October and November 2021 (see SI Table B2 for the exact date for each country). A one standard deviation increase in patience is associated with 12.0 percentage points higher rate of vaccination $(95 \%$ CI based on heteroskedasticity-consistent standard errors: 8.30 - 15.70 pp). Positive correlations can also be seen within continents, suggesting a nearly universal relationship. The results are unchanged if we use the percentage fully vaccinated as our proxy for the vaccination rate (SI Figure C1), or if we consider vaccination rates at earlier points in time (SI Figure C2). 


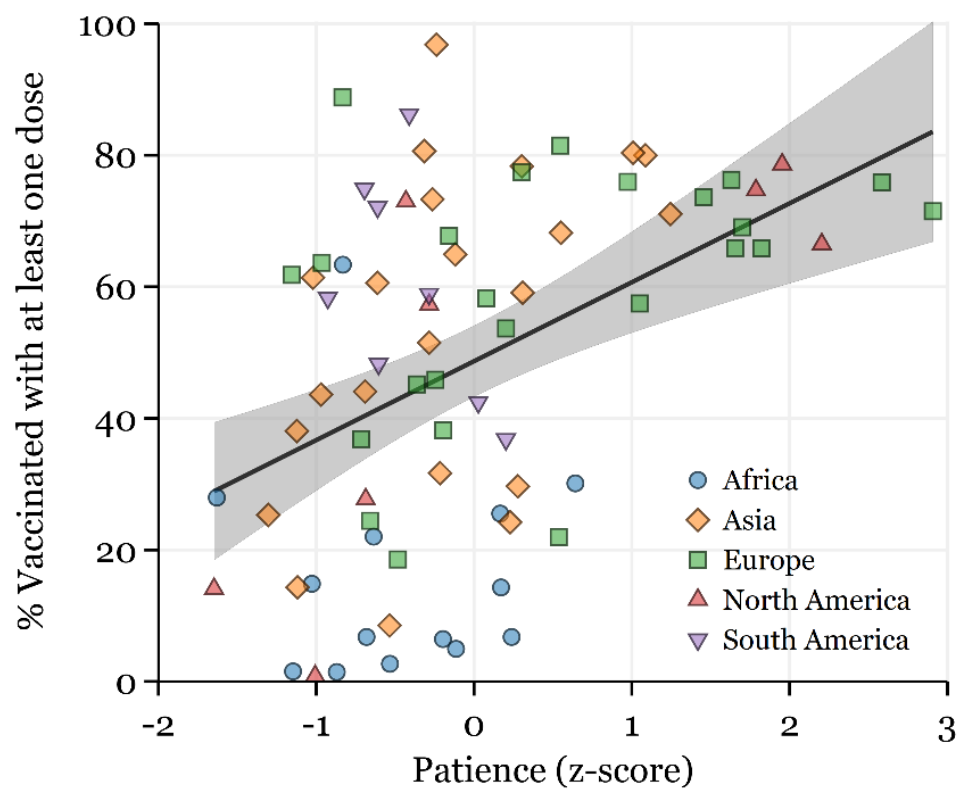

Fig. 1. Global variation in vaccination rates and patience. $R^{2}=0.21$; Pearson's $r=0.45 ; p<$ 0.001 .

Figure 2 and Table 1 show that none of the risk and social preferences measures from the GPS are as strongly correlated with vaccination rates as patience. Pearson's $r$ for the other measures ranges from 0.06 to 0.33 in absolute value, relative to $r=0.45$ for patience. The predictive power of patience is nearly twice as large as that of the next most important variable (with $R^{2}$ values of 0.21 vs. 0.11 for patience and trust, respectively). 

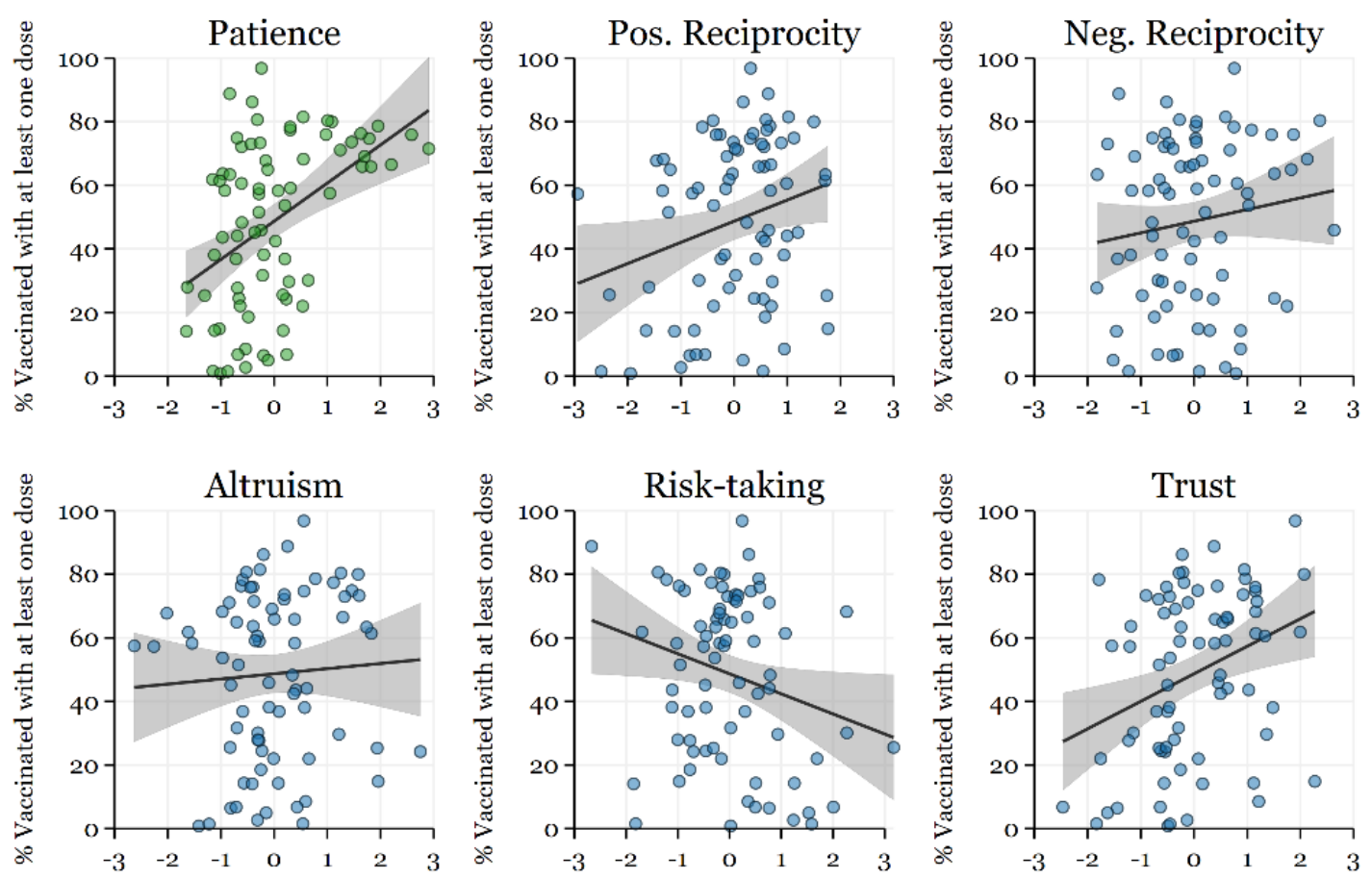

Fig. 2. Scatterplots of unconditional relationships between vaccination rates, and patience, risk, and social preferences. Independent variables are standardized.

Table 1. Correlations between vaccination rates and patience, risk, and social preferences.

\begin{tabular}{lcc}
\hline Variable & $\boldsymbol{R}^{2}$ & Pearson's $\boldsymbol{r}$ \\
\hline Patience & 0.21 & 0.45 \\
Positive Reciprocity & 0.06 & 0.25 \\
Negative Reciprocity & 0.02 & 0.14 \\
Altruism & 0.00 & 0.06 \\
Risk-taking & 0.06 & -0.24 \\
Trust & 0.11 & 0.33 \\
\hline
\end{tabular}

Risk and social preferences do not explain away the correlation between patience and vaccination. The coefficient of patience is virtually unchanged when we control for any or all measures of risk and social preferences (SI Figure C3). When we control for each GPS measure, the $p$-values from Wald tests for the equality of coefficients for patience are as follows ([control variable included: Wald $p$-value]): [positive reciprocity: 0.87], [negative reciprocity: 0.82], [altruism: 0.92], [trust: 0.19], [all GPS variables: 0.78]. The only significant difference arises when we control for risk tolerance $(p=0.03)$, which causes the coefficient of patience to increase, such that risk tolerance cannot explain away the correlation between patience and vaccination. The partial $R^{2}$ of patience (SI Table C1) is also virtually unchanged when we control for any or all measures of risk and social preferences. 
Patience thus explains global vaccination rates above and beyond attitudes towards risk, reciprocity, altruism, and trust.

Other factors, aside from risk and social preferences, could potentially explain away the relationship between patience and vaccination; we control for an extensive set of covariates in SI Table C2. We include: a full set of continent dummies, such that we are comparing more or less patient countries within the same geographic area; a battery of health-related variables (COVID19 cases per capita measured at the same date as the vaccination data (see SI Table C2), the number of hospital beds per thousand people, the median age of the population, and a dummy for prior experience with either the MERS or SARS pandemics); differences in income per capita, education, population density, the quality of political institutions, optimism, and, crucially, differences in vaccination policy. Holding all of these factors constant, in addition to risk and social preferences, approximately $82 \%$ of the variation in global vaccination rates is explained; patience is still highly significant, and its coefficient is still meaningfully large $(\beta=4.98 ; p<0.05$; see SI Table C2 and added-variable plot in SI Figure C4). Note that this is a very likely lower bound, since many of the controls we include suffer from what causal inference scholars term the 'bad control' problem (Angrist and Pischke 2009; Cinelli, Forney and Pearl 2021; see SI Figure C5 for an illustration): where a covariate $Z$ is an outcome of the independent variable $X$ whose effect on $Y$ we are interested in identifying, controlling for $Z$ leads to a downward bias in the coefficient of $X$. As Angrist and Pischke (2009, p. 64) note, good controls are "variables that we can think of having been fixed at the time the regressor of interest was determined." Education and economic development, in particular, are bad controls in this setting, as they were likely not fixed at the time patience was determined. Sunde et al. (2021) and Hanushek et al. (2021) convincingly show that more patience leads to higher willingness to invest in education, which has costs now but benefits later, in turn leading to more economic development.

One limitation of the analysis performed in this section is that the conventional test statistics rely on large sample approximations. We thus relax any distributional assumptions that may hold only asymptotically, and instead implement randomization inference, which allows us to estimate the actual distribution of test statistics in our data. The intuition dates back to Fisher's (1935) tea tasting experiment. Whereas a t-test compares the observed test statistic to Student's tdistribution, Fisherian randomization inference compares the observed test statistic to the distribution of test statistics that could have been obtained under all possible 'treatment' allocations. Comparing the observed test statistic to the distribution of all possible test statistics therefore yields an exact p-value, even in smaller samples. We thus generate random values for patience, then collect the coefficients of patience from a regression of vaccination rates on patience 
and covariates. We repeat this procedure 1,000 times in order to obtain the distribution of placebo patience coefficients, which we then compare to the coefficient of actual patience. We find that the coefficient of actual patience is significantly larger than that of placebo patience $(p<0.000)$, suggesting that our original estimates really are detecting the effect of patience, rather than that of an unobserved confounding variable.

\section{Study $1 \mathrm{~b}$ results: patience and vaccine uptake}

The above results establish that patience explains vaccination rates as of late October - early November 2021. However, it is possible that more patient countries also happen to be countries which started vaccinating earlier, and as a result, have reached higher vaccination rates by the time of this writing. We, therefore, estimate survival models in Study 1b. Our hypothesis is that people in more patient countries are more likely to sign up for vaccination, such that the country is quicker to reach high levels of vaccination.

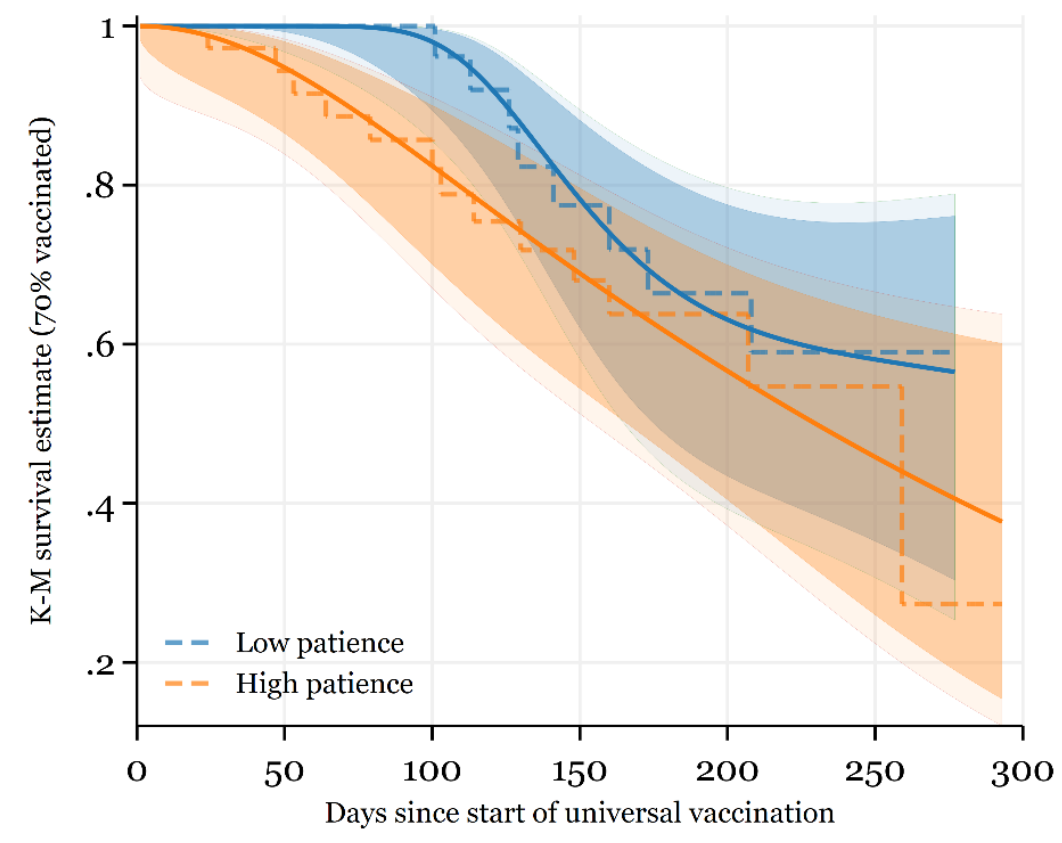

Fig. 3. Kaplan-Meier survival curves.

Notes. A 'failure' event consists in reaching $70 \%$ percent of the population vaccinated with one or more doses. Shaded areas represent $90 \%$ and $95 \%$ CIs, respectively.

Figure 3 displays Kaplan-Meir survival curves for above- and below-median patience countries, denoted 'High' and 'Low'. Event time runs from the day a country implements universal vaccination until the 'failure' event, which is defined as reaching the threshold of a $70 \%$ vaccination 
rate (other cut-offs are examined below). The correlation between higher patience and the likelihood of reaching high levels of vaccination is very stark. ${ }^{5}$

In Figure 4, we present hazard ratios from random-effects proportional hazards models, with standard errors clustered over countries. The failure event is defined as reaching thresholds of $60 \%, 65 \%$, or $70 \%$ vaccination. The hazard ratios are large, ranging from 1.41 to 3.58 approximately, with a median hazard ratio equal to 1.84. All are highly significant except one, for which $p=0.103$.

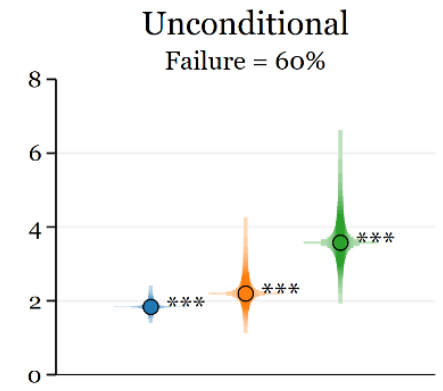

Conditional

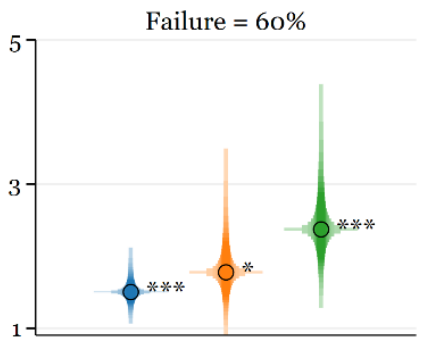

Entry:

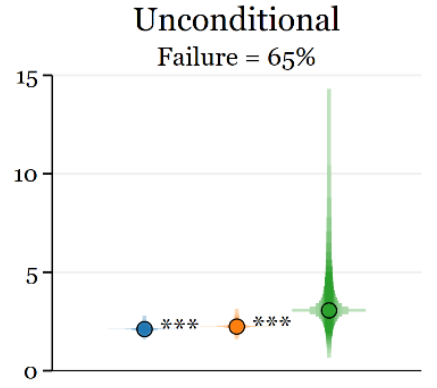

Conditional

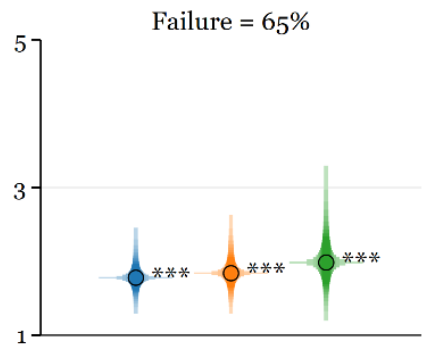

Start +30 days

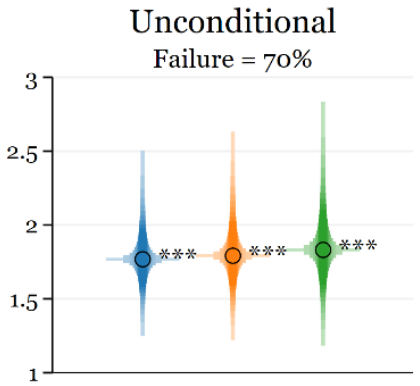

Conditional

Failure $=70 \%$

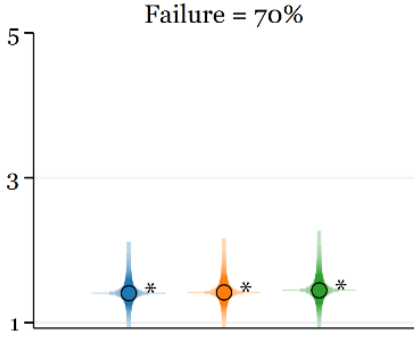

Start +60 days

Fig. 4. Hazard ratios into vaccination threshold of 60,65 , and $70 \%$, with time at risk beginning from the day the country implements universal vaccination (blue), +30 days (orange), or +60 days (green). ${ }^{* *},{ }^{* *}$, and $*$ denote significance at the 1,5 , and $10 \%$ levels, respectively.

The first row of Figure 4 presents unconditional hazard ratios; in the second row, we control for the large battery of controls from Study 1a (see SI Table C2 for a full list of controls). The blue confidence intervals correspond to an event time beginning on the day the country implements universal vaccination. One feature of Figure 3, however, is that more patient countries roll out universal vaccination early on. Thus, it could be the case that patient countries only reach high targets early because they had a head start; to 'level the playing field', so to speak, we also

\footnotetext{
${ }^{5}$ In SI Figure C6, we show the daily cumulative vaccination rate since vaccine is available in a country (OxCGRT vaccination policy $\mathrm{H} 7 \geq 1$ ). We again find that vaccination rate is consistently higher among countries with higher patience.
} 
report results where event time begins on the first day of universal vaccination +30 days (orange CIs in Figure 3) or +60 days (green CIs). The results are unaffected. ${ }^{6}$

As an alternative to survival models, we also examine whether the daily change in vaccination rates is related to patience. Like duration models, this will tell us whether vaccine uptake is faster in more patient countries, but without the need to define a threshold for a failure event. We find that a one standard deviation increase in patience is correlated with a $0.033 \%$ larger average daily change in vaccination rates (95\% CI: $0.021-0.046 ; p<0.001)$, such that it is clear that vaccine uptake is faster in more patient countries.

\section{Study 2a results: patience and attitudes towards vaccination in the $2009 \mathrm{H} 1 \mathrm{~N} 1$ pandemic}

Our next question is whether the link between and vaccination is specific to the COVID-19 pandemic. We turn our attention to the most recent previous pandemic: the 2009 outbreak of the swine influenza virus H1N1/09. While we are not aware of data on vaccination against swine flu, the European Commission did run a special iteration of its long-running Eurobarometer opinion poll in November 2009, which asked 28,663 respondents across 30 countries the following question: "Do you believe the pandemic (H1N1) flu vaccine will be effective and safe or not?". We matched these data to the GPS at the sub-national level for 17,329 Eurobarometer respondents across 138 sub-national regions of 17 countries (see 'Materials and Methods'). We can therefore study whether regional-level patience predicted attitudes towards vaccination in an earlier pandemic.

A key advantage of using regional data for Europe is that European regions are much more alike than other countries around the world. Thus, the potential for unobserved confounders to drive any relationship we might observe is likely smaller than in a cross-country setting. A second advantage is that Europeans, by global standards, tend to be quite patient (Falk et al. 2018; see also Figure 1 above). Thus, we can ascertain whether variation in patience matters for attitudes towards vaccination even at high levels of patience.

Our dependent variable is the percentage of respondents, at the sub-national region level, who answered "Yes" to the Eurobarometer question as to whether the H1N1 vaccine would be safe and effective. Figure 5 plots the correlations between our dependent variable and each of time, risk, and social preference measures, conditional on all other measures. A one standard

\footnotetext{
${ }^{6}$ In a similar vein, SI Figure C7 shows that our results also hold if we employ an alternate construction of event time, where event time begins instead from the date of first vaccination or the date the country clears vaccination rates of $5 \%$ or $10 \%$.
} 
deviation increase in patience is associated with an 8 p.p. increase in the regional-level share of respondents who agree the H1N1 vaccine will be safe and effective. The coefficient of patience is nearly 8 times as large as that of the next largest variable (positive reciprocity). All other GPS measures have precisely estimated zero effects, with $p$-values ranging from 0.60 to 0.93 and confidence intervals approximately centred around zero. These patterns are unchanged when we control for differences in economic development across regions (available upon request). We thus conclude that the association between patience and vaccination is not coincidental to the COVID19 pandemic but applies to the swine flu pandemic as well.
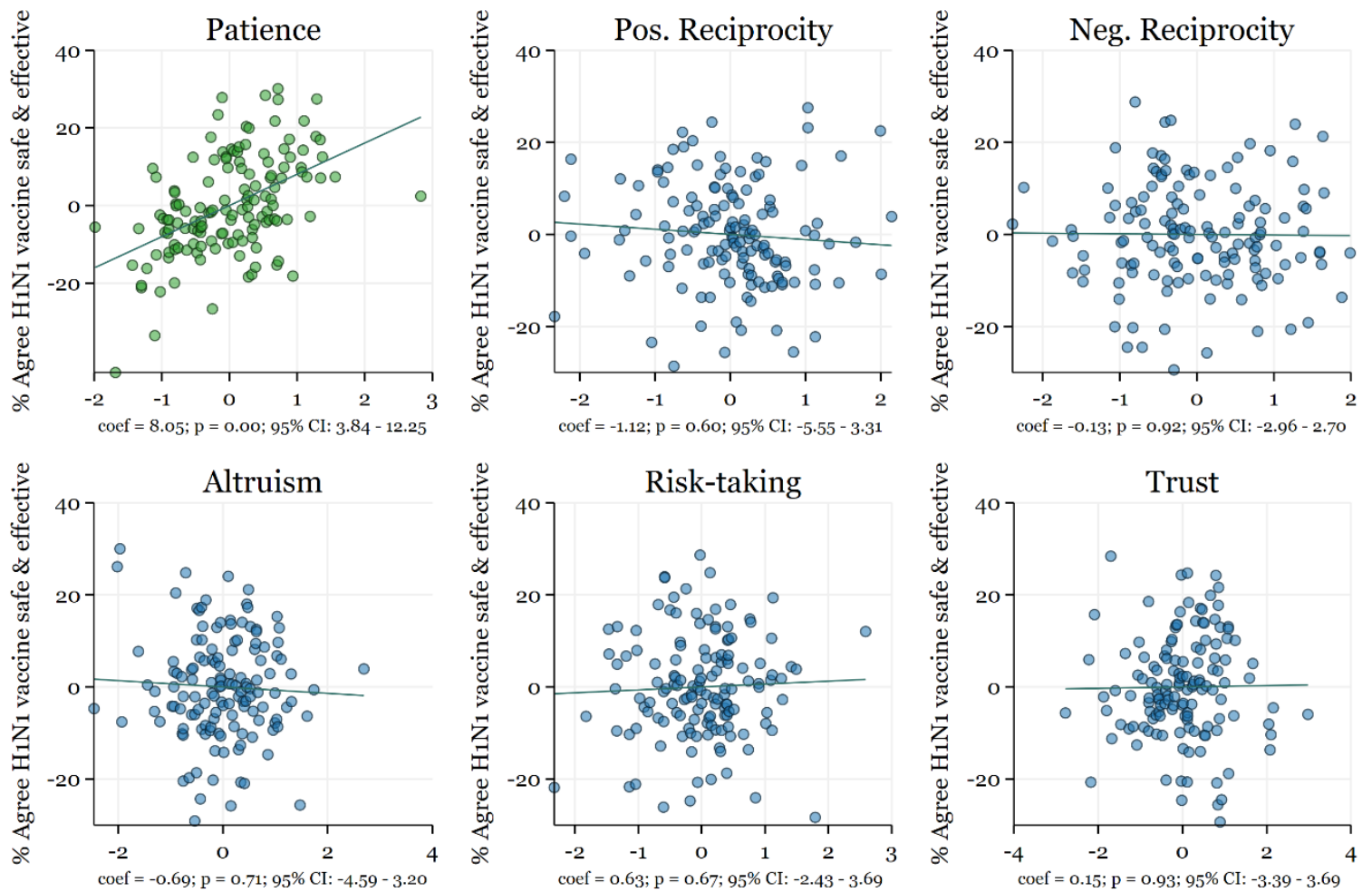

Fig. 5. Added-variable plots: infant vaccinations and patience, risk, and social preferences. The added-variable plot for each variable is conditional on all other variables. Independent variables are standardized. 95\% CIs based on heteroskedasticiy-consistent SEs clustered over countries.

\section{Study $2 b$ results: patience and infant vaccinations}

So far, we have shown that patience predicts vaccination during a pandemic (Study 1) and attitudes towards the safety and effectiveness of vaccination during a different pandemic (Study 2a), such that our results are demonstrably not peculiar to a single pandemic. Still, while pandemic preparedness is important for the future, ideally, we would like to understand whether patience 
has any bearing on 'business-as-usual' infant vaccinations. We think this is an important question in the face of the rising global movement questioning the safety and effectiveness of all vaccines, which has led to the resurgence of previously eradicated diseases such as measles (Fefferman and Naumova 2015; Giambi et al. 2018).

In Study 2b, we therefore examine whether patience is associated with 12 common infant vaccinations (tuberculosis, polio, measles, rubella, rotavirus, yellow fever, diphtheria, tetanus, pertussis, hepatitis B, pneumococcal disease, and haemophilus influenzae type B; see 'Materials and Methods'). Figure 6 plots the correlations between the percentage of vaccinated 1-year old infants (averaged across the 12 vaccinations), and time, risk, and social preference measures, conditional on all other measures, for the same sample of countries as that of Study 1, with the exception of Bolivia, for which vaccination data are not available.
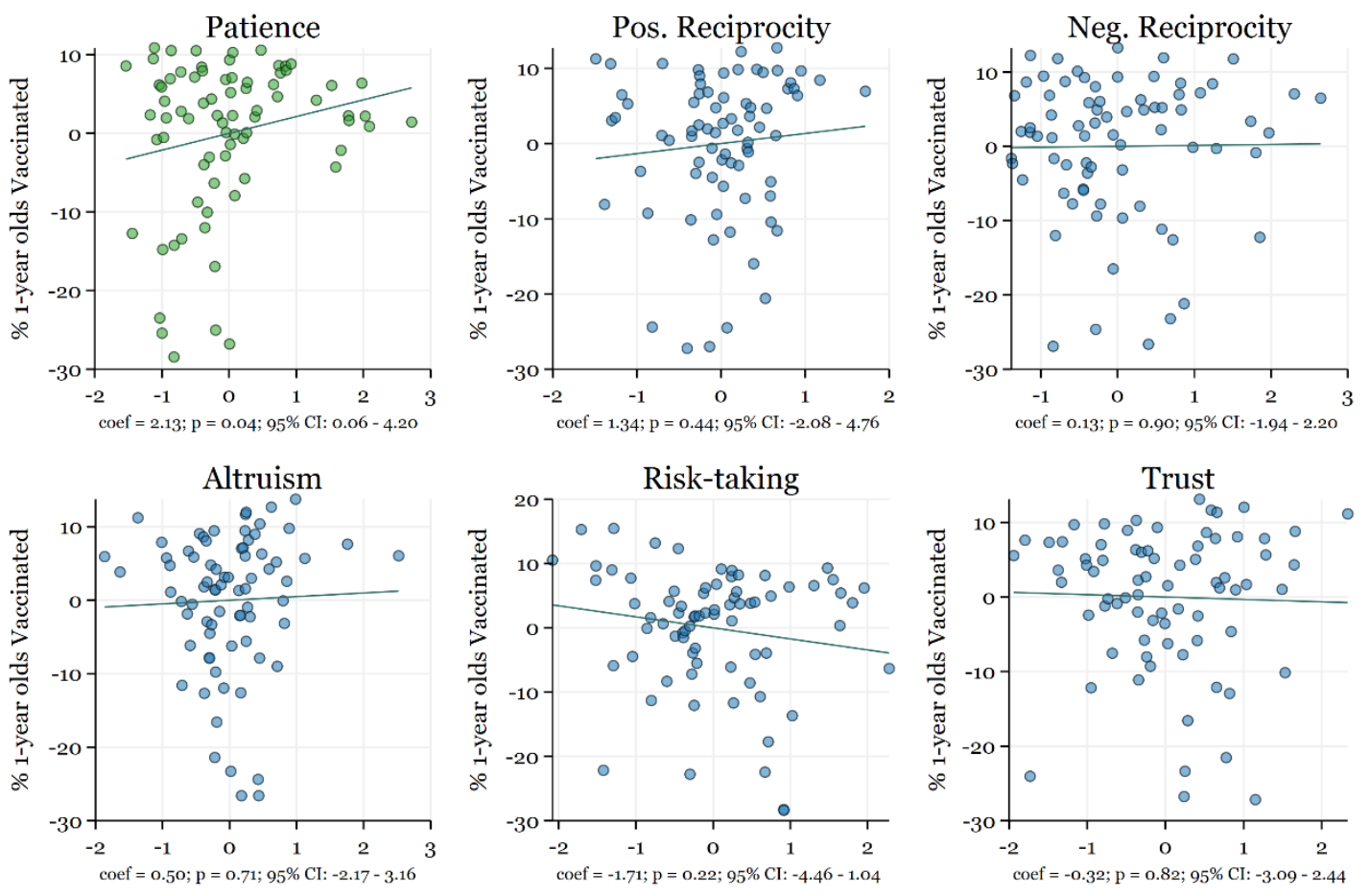

Fig. 6. Added-variable plots: infant vaccinations and patience, risk, and social preferences. The added-variable plot for each variable is conditional on all other variables. Independent variables are standardized. 95\% CIs based on heteroskedasticiy-consistent SEs.

Patience is the only significant predictor of vaccination. A one standard deviation increase in patience is associated with a 2.13 p.p. increase in the share of vaccinated infants $(p=0.04)$. Risk and social preferences are all insignificant, with $p$-values ranging from 0.22 to 0.90 . Thus, we can see that patience predicts vaccination above and beyond all other behavioural decision-making parameters, and does so in non-pandemic, 'business-as-usual' times. An important limitation is 
that this finding is not robust to controlling for per capita GDP. While it is not surprising that income levels are a powerful determinant of infant vaccinations, one should keep in mind that controlling for income will 'block' the path from patience to vaccination (SI Figure C5), since income is itself an outcome of patience (Sunde et al. 2021).

\section{Comparison of results across studies}

In each of the three cross-sectional studies $(1 \mathrm{a}, 2 \mathrm{a}, 2 \mathrm{~b})$ above, the dependent variable was percentage vaccinated or percentage agreeing that a vaccine was safe and effective. The interpretation of the correlation between the z-score of patience and each of these dependent variables is straightforward; comparing results across studies is less so. To facilitate such a comparison, we re-run our main models, this time regressing the z-score of the dependent variables on the full set of the $z$-scores of time, risk, and social preferences. Doing so allows us to gauge whether the effects we document are consistent between studies. Figure 7 shows that this is indeed the case. The effects in Study $1 \mathrm{a}$ and $2 \mathrm{a}$ are quite similar, with coefficients equal to 0.47 and 0.58 respectively. The Study $2 \mathrm{~b}$ coefficient is smaller, but in a similar order of magnitude $(0.17)$.

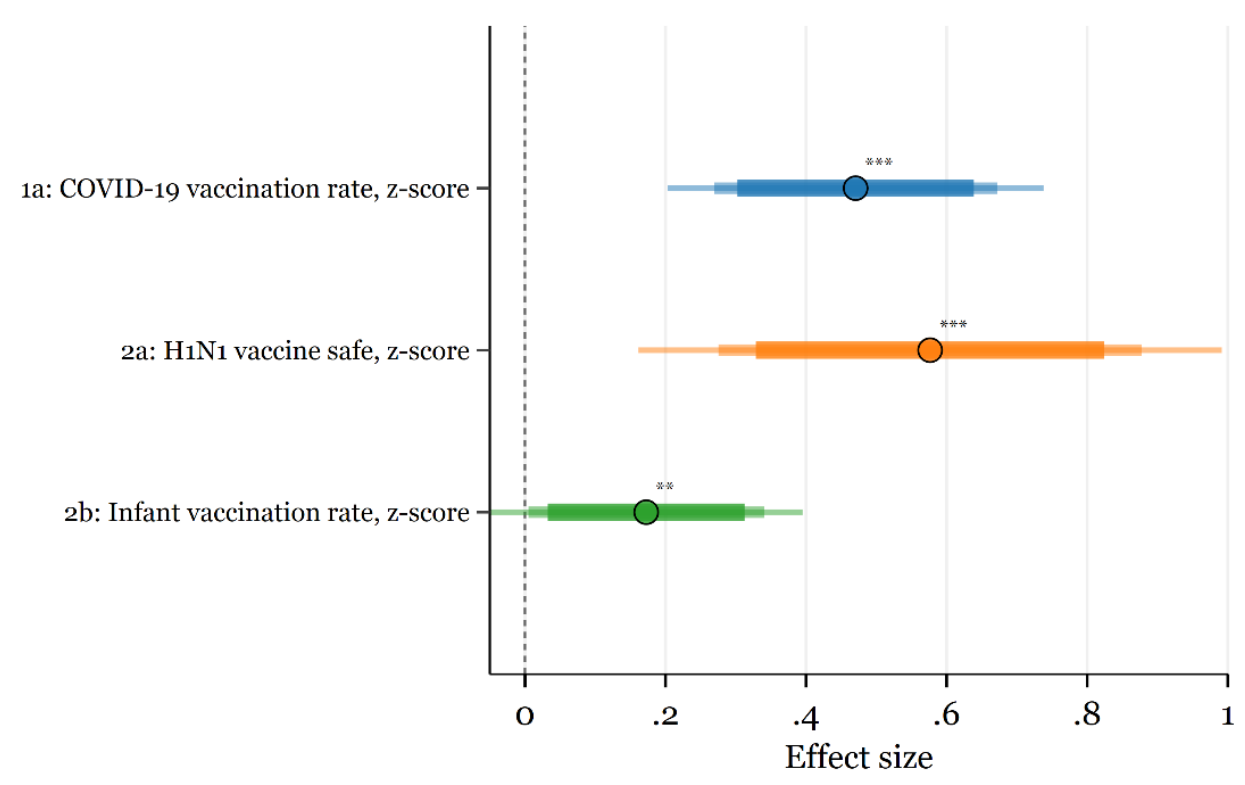

Fig. 7. Coefficients of Patience across studies. Error bars represent 99\%, 95\%, and 90\% CIs, respectively. ${ }^{* * *} \mathrm{p}<0.01,{ }^{* *} \mathrm{p}<0.05$.

\section{Limitations}

Although the correlation between patience and vaccination survives a large number of robustness checks, we cannot entirely rule out the possibility that a third unobserved variable causes both 
higher patience and higher vaccination. In our opinion, this is unlikely, as we control for other important decision-making parameters (risk and social preferences) and other health, development, and political variables.

Another limitation is that our data do not represent all countries around the world. The 76 countries included do, however, account for approximately $87 \%$ of the world population. Still, we should point out that since policymaking generally happens at the country level, one should exercise caution when devising policies for an individual country and consider the whole range of contextual factors specific to each country.

\section{Conclusion}

We have found strong support for the hypothesis that patience leads to higher vaccination rates and more positive attitudes towards vaccination. The hypothesis was tested in cross-sections of countries (Studies 1a and 2b) and sub-national regions (Study 2a) as well as in country-level duration models (Study 1b). Our Study 1a estimates, in particular, show a large role for patience even as over $80 \%$ of the variation in global vaccination rates as of late October - early November 2021 is accounted for.

Importantly, our results cannot be explained away by risk and social preferences (positive reciprocity, negative reciprocity, altruism, and trust), or by cross-country differences in health, economic development, vaccine availability, or political institutions. Equally importantly, risk and social preferences, according to our estimates, are much less important than patience in explaining both actual vaccination decisions and attitudes towards vaccination. Our results thus suggest that, in pandemic and non-pandemic times alike, vaccine messages appealing to patience, which should emphasize the future benefits of vaccination, are a worthwhile and urgently needed avenue of investigation.

\section{Materials and Methods}

\section{Data availability}

Replication data will be made available on the Open Science Framework when this article is accepted for publication.

\section{Vaccination rates}

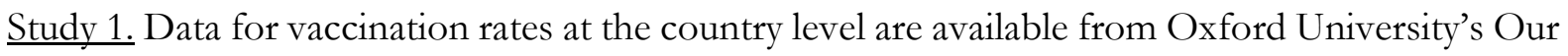
World in Data (OWID) initiative, specifically OWID's COVID-19 vaccination dataset (Mathieu 
et al. 2021). We use the percentage of the population with at least one dose of vaccination as a proxy for the vaccination rate. We interpolate missing values using the geometric growth rate; the results are robust to using linear interpolation or not interpolating missing values.

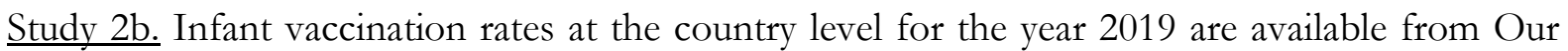
World in Data at https://ourworldindata.org/vaccination. We calculate a country's infant vaccination rate as the average rate of vaccination across all vaccines.

\section{COVID-19 Vaccination policy}

The Oxford Coronavirus Government Response Tracker (OxCGRT, Hale et al. 2021) has been tracking vaccination policies around the world since the United Kingdom became the first country to roll out vaccinations in December 2020. Vaccination policy is a categorical variable with the following levels: no availability; availability to one group (key workers, clinically vulnerable individuals, the elderly); availability to two of the three above groups; availability to all three of the above groups; availability to all three groups plus partial additional availability (based on broad groups, e.g., age brackets); universal availability. In the cross-sectional results (Study 1a), we control for the number of days, as of mid-2021, that a vaccine has been universally available or available to broad groups (e.g., age brackets).

\section{Attitudes towards H1N1 vaccine}

Flash Eurobarometer 287 (European Commission 2011), conducted in November 2009, asked 28,663 respondents across 30 European countries the following question: "Do you believe the pandemic (H1N1) flu vaccine will be effective and safe or not?". We matched these data to the GPS at the sub-national level for 17,329 Eurobarometer respondents across 138 sub-national regions of 17 countries. Data for Austria, Germany, Italy, Poland, Spain, and the United Kingdom corresponds to NUTS-1 regions on the European Union's Nomenclature of Territorial Units for Statistics classification. Data for Czechia, Finland, Greece, Hungary, Lithuania, the Netherlands, Portugal, Romania, Sweden, and Switzerland, are at the NUTS-2 level, while data for Estonia are at the NUTS-3 level.

\section{Global Preferences Survey (GPS)}

The GPS (Falk et al. 2018) furnishes data for our measures of patience, risk tolerance, altruism, trust, and positive and negative reciprocity. The GPS was specifically designed to be (i) experimentally validated, such that GPS measures reflect how individuals behave in incentivized 
laboratory experiments, and (ii) comparable across countries, as monetary stakes were adjusted to reflect differences in living standards. See Falk et al. $(2016,2018)$ for more details.

\section{Control variables}

Per capita GDP, population density, the percentage of the population aged 65 or older, the death rate from cardiovascular diseases, COVID-19 cases per capita, and hospital beds per thousands are all from Mathieu et al. (2021). Years of schooling, the level of democracy, and median age were sourced from the Quality of Government dataset (Teorell et al. 2017). The primary sources are, respectively, Barro and Lee (2013), Marshall and Gurr (2020), and World Health Organization (2020). Optimism comes from Gallagher et al. (2013), and is the mean response to Cantril's future ladder question, as collected by the Gallup World Poll (for details, see https://news.gallup.com/poll/122453/understanding-gallup-uses-cantril-scale.aspx). Experience with MERS and/or SARS is from Bickley et al. (2021).

Summary statistics: See SI Table B3.

\section{References}

Andreoni, J., \& Sprenger, C. (2012). Risk preferences are not time preferences. American Economic Review, 102(7), 3357-76.

Antia, A., Ahmed, H., Handel, A., Carlson, N. E., Amanna, I. J., Antia, R., \& Slifka, M. (2018). Heterogeneity and longevity of antibody memory to viruses and vaccines. PLoS Biology, 16(8), e2006601.

Aschwanden, C. (2020). The false promise of herd immunity for COVID-19. Nature, 587, 26-28.

Barro, R. J., \& Lee, J. W. (2013). A new data set of educational attainment in the world, 1950-2010. Journal of Development Economics, 104, 184-198.

Burton-Chellew, M. N., \& West, S. A. (2013). Prosocial preferences do not explain human cooperation in public-goods games. Proceedings of the National Academy of Sciences, 110(1), 216-221.

Bickley, S. J., Chan, H. F., Skali, A., Stadelmann, D., \& Torgler, B. (2021). How does globalization affect COVID-19 responses?. Globalization and Health, 17(1), 1-19.

Cinelli, C., Forney, A., \& Pearl, J. (2020). A crash course in good and bad controls. Available at SSRN, 3689437.

Curry, O. S., Price, M. E., \& Price, J. G. (2008). Patience is a virtue: Cooperative people have lower discount rates. Personality and Individual Differences, 44(3), 780-785. 
Davids, A. (1969). Ego functions in disturbed and normal children: Aspiration, inhibition, time estimation, and delayed gratification. Journal of Consulting and Clinical Psychology, 33(1), 6170. https://doi.org/10.1037/h0027338

Dohmen, T., Falk, A., Huffman, D., \& Sunde, U. (2010). Are risk aversion and impatience related to cognitive ability?. American Economic Review, 100(3), 1238-60.

Espín, A. M., Brañas-Garza, P., Herrmann, B., \& Gamella, J. F. (2012). Patient and impatient punishers of free-riders. Proceedings of the Royal Society B: Biological Sciences, 279(1749), 4923-4928.

European Commission (2011). Flash Eurobarometer 287 (Influenza H1N1). GESIS data archive, Cologne. ZA5222 data file version 1.0.0, https:// doi.org/10.4232/1.10224.

Falk, A., Becker, A., Dohmen, T., Enke, B., Huffman, D., \& Sunde, U. (2018). Global evidence on economic preferences. The Quarterly Journal of Economics, 133(4), 1645-1692.

Falk, A., Becker, A., Dohmen, T. J., Huffman, D., \& Sunde, U. (2016). The preference survey module: A validated instrument for measuring risk, time, and social preferences. Mimeo.

Fefferman, N. H., \& Naumova, E. N. (2015). Dangers of vaccine refusal near the herd immunity threshold: a modelling study. The Lancet Infectious Diseases, 15(8), 922-926.

Fehr, E., \& Leibbrandt, A. (2011). A field study on cooperativeness and impatience in the tragedy of the commons. Journal of Public Economics, 95(9-10), 1144-1155.

Frederick, S., Loewenstein, G., \& O'donoghue, T. (2002). Time discounting and time preference: A critical review. Journal of Economic Literature, 40(2), 351-401.

Gallagher, M. W., Lopez, S. J., \& Pressman, S. D. (2013). Optimism is universal: Exploring the presence and benefits of optimism in a representative sample of the world. Journal of Personality, 81(5), 429-440.

Giambi, C., Fabiani, M., D'Ancona, F., Ferrara, L., Fiacchini, D., Gallo, T., ... \& Rota, M. C. (2018). Parental vaccine hesitancy in Italy-results from a national survey. Vaccine, 36(6), 779-787.

Hale, T., Angrist, N., Goldszmidt, R., Kira, B., Petherick, A., Phillips, T., ... \& Tatlow, H. (2021). A global panel database of pandemic policies (Oxford COVID-19 Government Response Tracker). Nature Human Behaviour, 5(4), 529-538.

Hanushek, E. A., Kinne, L., Lergetporer, P., \& Woessmann, L. (2021). Patience, Risk-Taking, and Human Capital Investment across Countries. Economic Journal, forthcoming.

Henrich, J., Heine, S. J., \& Norenzayan, A. (2010). Most people are not WEIRD. Nature, 466(7302), 29-29.

Jevons, W.S. (1888). The Theory of Political Economy. London: Macmillan.

Korn, L., Böhm, R., \& Betsch, C. (2021). Reply to Rabb et al.: Why promoting COVID-19 vaccines with community immunity is not a good strategy (yet). Proceedings of the National Academy of Sciences, 118(14). 
Klineberg, S. L. (1968). Future time perspective and the preference for delayed reward. Journal of Personality and Social Psychology, 8(3p1), 253.

Marshall, M. G., \& Gurr, T. R. (2020). Polity v project, political regime characteristics and transitions, 1800-2018. Center for Systemic Peace.

Mathieu, E., Ritchie, H., Ortiz-Ospina, E., Roser, M., Hasell, J., Appel, C., ... \& Rodés-Guirao, L. (2021). A global database of COVID-19 vaccinations. Nature Human Behaviour, 5, 947-953.

Mischel, W., \& Ebbesen, E. B. (1970). Attention in delay of gratification. Journal of Personality and Social Psychology, 16(2), 329-337. https://doi.org/10.1037/h0029815

Nichol, K. L., Nordin, J. D., Nelson, D. B., Mullooly, J. P., \& Hak, E. (2007). Effectiveness of influenza vaccine in the community-dwelling elderly. New England Journal of Medicine, 357(14), 13731381.

Rabb, N., Glick, D., Houston, A., Bowers, J., \& Yokum, D. (2021). No evidence that collectivegood appeals best promote COVID-related health behaviors. Proceedings of the National Academy of Sciences, 118(14).

Rae, J. (1834). The Sociological Theory of Capital. London: Macmillan.

Rosati, A. G., Stevens, J. R., Hare, B., \& Hauser, M. D. (2007). The evolutionary origins of human patience: temporal preferences in chimpanzees, bonobos, and human adults. Current Biology, 17(19), 1663-1668.

Snowden, F. M. (2019). Epidemics and Society. Yale University Press.

Solís Arce, J. S., Warren, S. S., Meriggi, N. F., Scacco, A., McMurry, N., Voors, M., ... \& Omer, S. B. (2021). COVID-19 vaccine acceptance and hesitancy in low-and middle-income countries. Nature Medicine.

Stevens, J. R., Hallinan, E. V., \& Hauser, M. D. (2005). The ecology and evolution of patience in two New World monkeys. Biology Letters, 1(2), 223-226.

Sunde, U., Dohmen, T., Enke, B., Falk, A., Huffman, D., \& Meyerheim, G. (2021). Patience and comparative development. Review of Economic Studies (forthcoming).

Teorell, J., Sundström, A., Holmberg, S., Rothstein, B., Alvarado Pachon A., \& Dalli, C.M. (2021). The Quality of Government Standard Dataset, version Jan21. University of Gothenburg: The Quality of Government Institute, http://www.qog.pol.gu.se doi:10.18157/qogstdjan21

Triandis, H. C., Malpass, R. S., \& Davidson, A. R. (1973). Psychology and culture. Annual Review of Psychology, 24(1), 355-378.

World Health Organization. (2020). Global health observatory data repository. Retrieved from http://www.who.int/gho/en/ 


\section{SUPPLEMENTARY INFORMATION}

For online publication

\section{APPENDIX A: BACKGROUND INFORMATION}

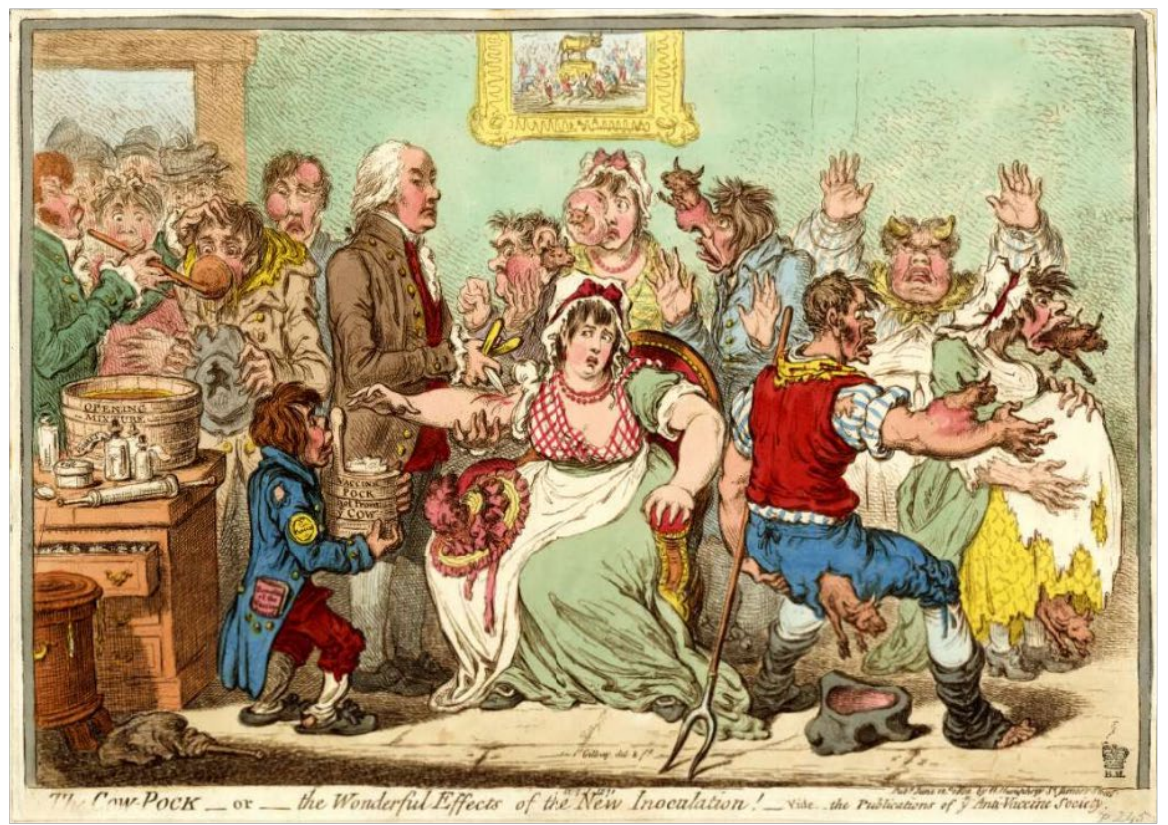

Figure A1. Satirical Cartoon Expressing Anxieties Around Vaccination, dated June 1802: The Cow-Pock-or-the Wonderful Effects of the New Inoculation!

Notes: Object "The Cow-Pock-or-the Wonderful Effects of the New Inoculation!- June 12, 1802. Available at The British Museum (https://www.britishmuseum.org/collection/object/P 1851-0901-1091). Description: "scene in a vaccine institution; poor patients crowd in through a doorway on the left; in the room are those whose treatment has had dire consequences. A comely and frightened young woman sits in an armchair in the centre, the doctor (...) holds her right arm and gashes it with his knife, while a deformed and ragged boy holds up a bucket of 'Vaccine Pock hot from ye Cow'. A charity-schoolboy's oval badge on his sleeve is inscribed 'St Pancras'; from his coat pocket projects a pamphlet: 'Benefits of the Vaccine Process'. From the patients miniature cows sprout or leap. A pregnant woman (right) stands in profile to the right, a cow issues from her mouth, another from below her ragged petticoat. A man dressed as a butcher registers despair at the horns which sprout from his forehead. A labourer with a pitchfork sees a cow bursting from a swelling on his arm while another breaks through his breeches; cows struggle through huge swellings on nose, ear, and cheek. Another patient has only reached the stage of large carbuncles on forehead and chin. The doctor's medicine-chest and a close-stool stand on the left. On the chest are bottles, a syringe, and a tub of 'Opening Mixture'. A haughty assistant ladles contemptuously into the mouths of the patients as they crowd into the room. On the wall is a picture: a crowd of kneeling worshippers pay homage to the statue of the golden calf. The scene combines fantasy and realism. After the title: 'Vide - the Publications of ye Anti-Vaccine Society"'. 
a)

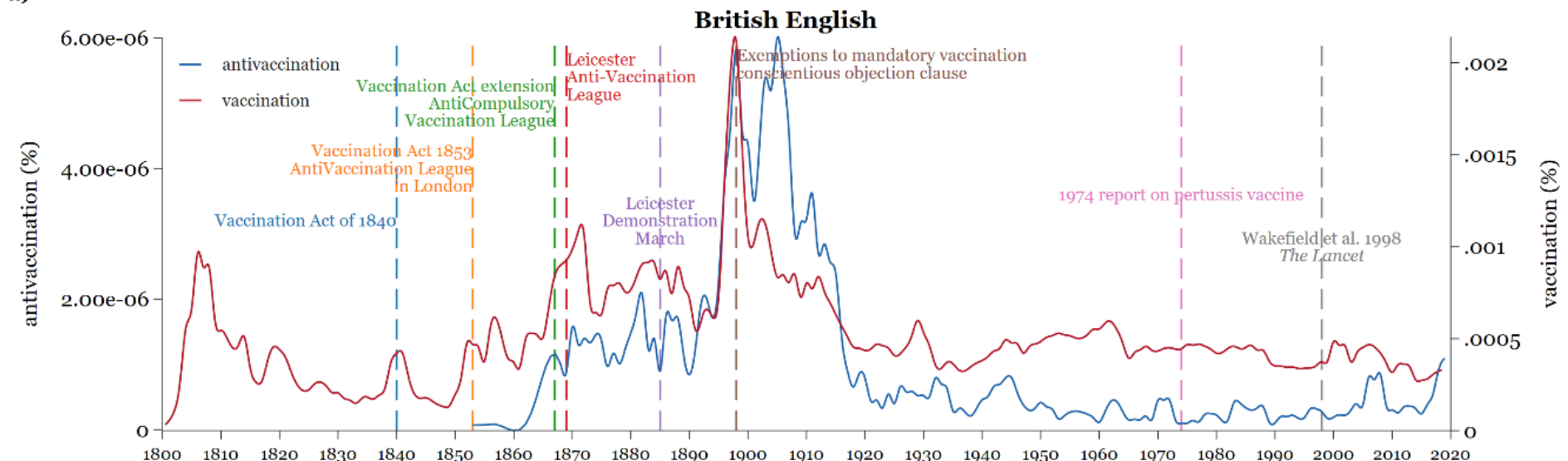

American English

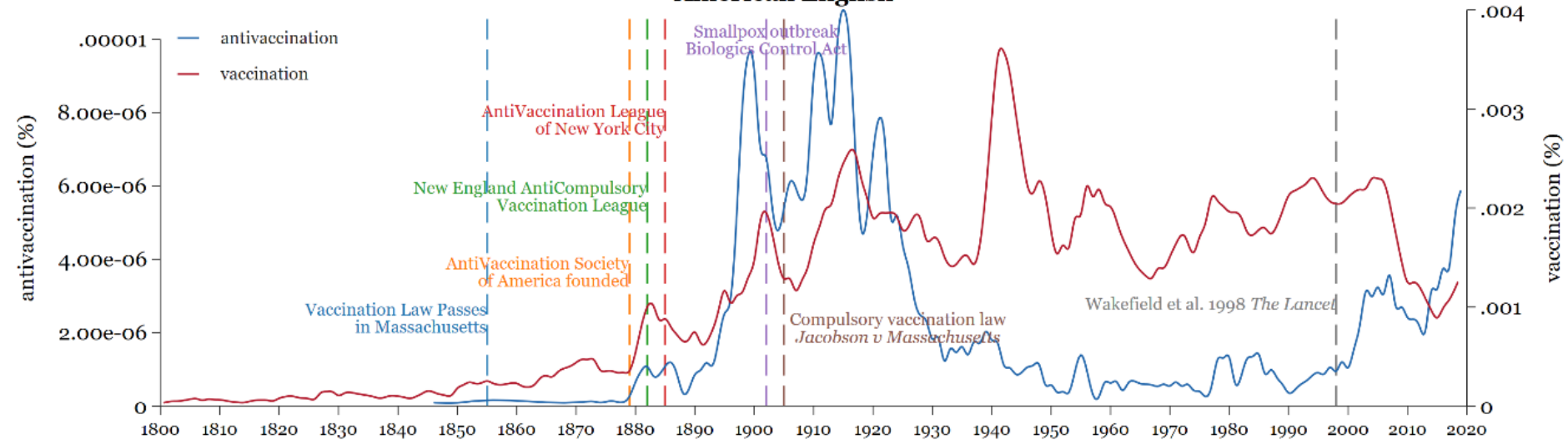

Source: Author's own work using the Google Books Ngram viewer (version 3). Usage is calculated as the yearly occurrence of the word by the number of unigrams (the total word frequency of words each year in all books). Usage is smoothed with a 3 -year moving average smoother (1 year before; current year; 1 year after). 


\section{APPENDIX B: DATA SOURCES AND DESCRIPTIVE STATISTICS}

Table B1. Study 1: Countries included and global distribution of patience.

\begin{tabular}{|c|c|c|c|c|c|}
\hline Country & Patience (z-score) & $\mathbf{N}$ & Country & Patience (z-score) & $\mathbf{N}$ \\
\hline Afghanistan & -0.546 & 1000 & Italy & 0.291 & 1004 \\
\hline United Arab Emirates & -0.249 & 1000 & Jordan & -1.133 & 1000 \\
\hline Argentina & -0.622 & 1000 & Japan & 0.290 & 1000 \\
\hline Australia & 1.772 & 1002 & Kazakhstan & -0.701 & 999 \\
\hline Austria & 1.641 & 1001 & Kenya & -0.208 & 1000 \\
\hline Bangladesh & 0.217 & 999 & Cambodia & -0.326 & 1000 \\
\hline Bosnia Herzegovina & -0.670 & 1004 & South Korea & 0.995 & 1000 \\
\hline Bolivia & 0.190 & 998 & Sri Lanka & -0.275 & 1000 \\
\hline Brazil & -0.705 & 1003 & Lithuania & -0.169 & 999 \\
\hline Botswana & 0.630 & 1000 & Morocco & -0.842 & 1000 \\
\hline Canada & 1.938 & 1001 & Moldova & 0.524 & 1000 \\
\hline Switzerland & 1.807 & 1000 & Mexico & -0.295 & 1000 \\
\hline Chile & -0.422 & 1003 & Malawi & -0.125 & 1000 \\
\hline China & 1.073 & 2574 & Nigeria & -0.544 & 1000 \\
\hline Cameroon & -1.157 & 1000 & Nicaragua & -1.657 & 1000 \\
\hline Colombia & -0.937 & 1000 & Netherlands & 2.568 & 1000 \\
\hline Costa Rica & -0.443 & 1000 & Pakistan & -0.227 & 1004 \\
\hline Czech Republic & 1.036 & 1005 & Peru & -0.297 & 1000 \\
\hline Germany & 1.684 & 997 & Philippines & 0.265 & 1000 \\
\hline Algeria & 0.159 & 1022 & Poland & 0.191 & 999 \\
\hline Egypt & -1.037 & 1020 & Portugal & -0.844 & 998 \\
\hline Spain & 0.534 & 1000 & Romania & -0.727 & 994 \\
\hline Estonia & 0.066 & 1004 & Russia & -0.206 & 1498 \\
\hline Finland & 1.617 & 1000 & Rwanda & -1.639 & 1000 \\
\hline France & 0.962 & 1001 & Saudi Arabia & 0.538 & 1035 \\
\hline United Kingdom & 1.443 & 1030 & Serbia & -0.375 & 1023 \\
\hline Georgia & -1.313 & 1000 & Suriname & 0.016 & 504 \\
\hline Ghana & 0.226 & 1000 & Sweden & 2.892 & 1000 \\
\hline Greece & -0.975 & 1000 & Thailand & -0.623 & 1000 \\
\hline Guatemala & -0.697 & 1000 & Turkey & -0.130 & 1000 \\
\hline Croatia & -0.255 & 992 & Uganda & -0.692 & 1000 \\
\hline Haiti & -1.017 & 504 & Ukraine & -0.493 & 1000 \\
\hline Hungary & -1.166 & 1004 & United States & 2.189 & 1072 \\
\hline Indonesia & -0.980 & 1000 & Venezuela & -0.616 & 999 \\
\hline India & -0.296 & 2539 & Vietnam & 0.296 & 1000 \\
\hline Iran & -1.031 & 2507 & South Africa & 0.154 & 1000 \\
\hline Iraq & -1.129 & 1000 & Zimbabwe & -0.647 & 1000 \\
\hline Israel & 1.231 & 999 & & & \\
\hline
\end{tabular}


Table B2. Study 1a: latest available date for vaccination data, by country.

\begin{tabular}{|c|c|c|c|}
\hline Country & Date $(\mathrm{D} / \mathrm{M} / \mathrm{Y})$ & Country & Date (D/M/Y) \\
\hline Afghanistan & $31 / 10 / 21$ & Kazakhstan & $5 / 11 / 21$ \\
\hline Algeria & $1 / 11 / 21$ & Kenya & $25 / 10 / 21$ \\
\hline Argentina & $25 / 10 / 21$ & Lithuania & $5 / 11 / 21$ \\
\hline Australia & $5 / 11 / 21$ & Malawi & $1 / 11 / 21$ \\
\hline Austria & $5 / 11 / 21$ & Mexico & $31 / 10 / 21$ \\
\hline Bangladesh & $25 / 10 / 21$ & Moldova & $1 / 11 / 21$ \\
\hline Bolivia & $12 / 10 / 21$ & Morocco & $22 / 10 / 21$ \\
\hline Bosnia and Herzegovina & $16 / 10 / 21$ & Netherlands & $4 / 11 / 21$ \\
\hline Botswana & $7 / 11 / 21$ & Nicaragua & $24 / 10 / 21$ \\
\hline Brazil & $1 / 11 / 21$ & Nigeria & $31 / 10 / 21$ \\
\hline Cambodia & $24 / 10 / 21$ & Pakistan & $31 / 10 / 21$ \\
\hline Cameroon & $6 / 11 / 21$ & Peru & $4 / 11 / 21$ \\
\hline Canada & $5 / 11 / 21$ & Philippines & $7 / 11 / 21$ \\
\hline Chile & $7 / 11 / 21$ & Poland & $3 / 11 / 21$ \\
\hline China & $8 / 11 / 21$ & Portugal & $4 / 11 / 21$ \\
\hline Colombia & $29 / 10 / 21$ & Romania & $1 / 11 / 21$ \\
\hline Costa Rica & $1 / 11 / 21$ & Russia & $1 / 11 / 21$ \\
\hline Croatia & $18 / 10 / 21$ & Rwanda & $25 / 10 / 21$ \\
\hline Czechia & $22 / 10 / 21$ & Saudi Arabia & $25 / 10 / 21$ \\
\hline Egypt & $18 / 10 / 21$ & Serbia & $25 / 10 / 21$ \\
\hline Estonia & $18 / 10 / 21$ & South Africa & $31 / 10 / 21$ \\
\hline Finland & $1 / 11 / 21$ & South Korea & $1 / 11 / 21$ \\
\hline France & $5 / 11 / 21$ & Spain & $4 / 11 / 21$ \\
\hline Georgia & $16 / 10 / 21$ & Sri Lanka & $6 / 11 / 21$ \\
\hline Germany & $5 / 11 / 21$ & Suriname & $5 / 11 / 21$ \\
\hline Ghana & $31 / 10 / 21$ & Sweden & $6 / 11 / 21$ \\
\hline Greece & $25 / 10 / 21$ & Switzerland & $6 / 11 / 21$ \\
\hline Guatemala & $17 / 10 / 21$ & Tanzania & $1 / 11 / 21$ \\
\hline Haiti & $31 / 10 / 21$ & Thailand & $1 / 11 / 21$ \\
\hline Hungary & $1 / 11 / 21$ & Turkey & $25 / 10 / 21$ \\
\hline India & $24 / 10 / 21$ & Uganda & $1 / 11 / 21$ \\
\hline Indonesia & $1 / 11 / 21$ & Ukraine & $18 / 10 / 21$ \\
\hline Iran & $31 / 10 / 21$ & United Arab Emirates & $1 / 11 / 21$ \\
\hline Iraq & $29 / 10 / 21$ & United Kingdom & $5 / 11 / 21$ \\
\hline Israel & $5 / 11 / 21$ & United States & $5 / 11 / 21$ \\
\hline Italy & $5 / 11 / 21$ & Venezuela & $7 / 11 / 21$ \\
\hline Japan & $6 / 11 / 21$ & Vietnam & $1 / 11 / 21$ \\
\hline Jordan & $26 / 10 / 21$ & Zimbabwe & $1 / 11 / 21$ \\
\hline
\end{tabular}


Table B3. Summary statistics.

\begin{tabular}{|c|c|c|c|c|c|}
\hline Variable & $\mathbf{N}$ & Mean & SD & Min & Max \\
\hline COVID-19 vaccination rate, Oct.-Nov. 2021 & 76 & 48.69 & 26.41 & 0.83 & 96.81 \\
\hline COVID-19 vaccination rate, time-varying & 9,973 & 34.23 & 22.17 & 0.01 & 71.01 \\
\hline Infant vaccination rate, 2019 & 75 & 87.22 & 12.35 & 38.11 & 99.00 \\
\hline \multicolumn{6}{|l|}{ GPS measures, country-level } \\
\hline Patience (z-score) & 76 & 0.00 & 1.00 & -1.65 & 2.91 \\
\hline Positive reciprocity (z-score) & 76 & 0.00 & 1.00 & -2.94 & 1.77 \\
\hline Negative reciprocity (z-score) & 76 & 0.00 & 1.00 & -1.82 & 2.64 \\
\hline Altruism (z-score) & 76 & 0.00 & 1.00 & -2.63 & 2.75 \\
\hline Risk tolerance (z-score) & 76 & 0.00 & 1.00 & -2.67 & 3.17 \\
\hline Trust (z-score) & 76 & 0.00 & 1.00 & -2.46 & 2.27 \\
\hline \multicolumn{6}{|l|}{ GPS measures, regional-level } \\
\hline Patience (z-score) & 138 & 0.00 & 1.00 & -2.20 & 1.97 \\
\hline Positive reciprocity (z-score) & 138 & 0.00 & 1.00 & -3.10 & 2.45 \\
\hline Negative reciprocity (z-score) & 138 & 0.00 & 1.00 & -2.43 & 2.30 \\
\hline Altruism (z-score) & 138 & 0.00 & 1.00 & -2.79 & 2.00 \\
\hline Risk tolerance (z-score) & 138 & 0.00 & 1.00 & -2.83 & 2.94 \\
\hline Trust (z-score) & 138 & 0.00 & 1.00 & -2.48 & 2.59 \\
\hline Days with universal vaccination & 76 & 136.25 & 74.43 & 0.00 & 292.00 \\
\hline $\ln (\mathrm{GDP}$ per capita $)$ & 76 & 9.52 & 1.01 & 7.00 & 11.12 \\
\hline $\ln$ (Population density) & 76 & 4.35 & 1.26 & 1.16 & 7.14 \\
\hline Median age & 76 & 33.28 & 9.08 & 16.40 & 48.20 \\
\hline $\ln$ (cumulative COVID-19 cases per capita) & 76 & -3.55 & 1.59 & -9.61 & -1.81 \\
\hline Hospital beds per thousand & 74 & 3.26 & 2.70 & 0.50 & 13.05 \\
\hline Democracy index & 75 & 5.27 & 5.61 & -10.00 & 10.00 \\
\hline Years of schooling & 72 & 8.75 & 2.79 & 3.23 & 13.42 \\
\hline MERS / SARS & 76 & 0.08 & 0.27 & 0.00 & 1.00 \\
\hline $\ln$ (new COVID-19 cases per capita) & 9,970 & 3.90 & 2.00 & -5.30 & 8.12 \\
\hline
\end{tabular}




\section{APPENDIX C: ADDITIONAL RESULTS}

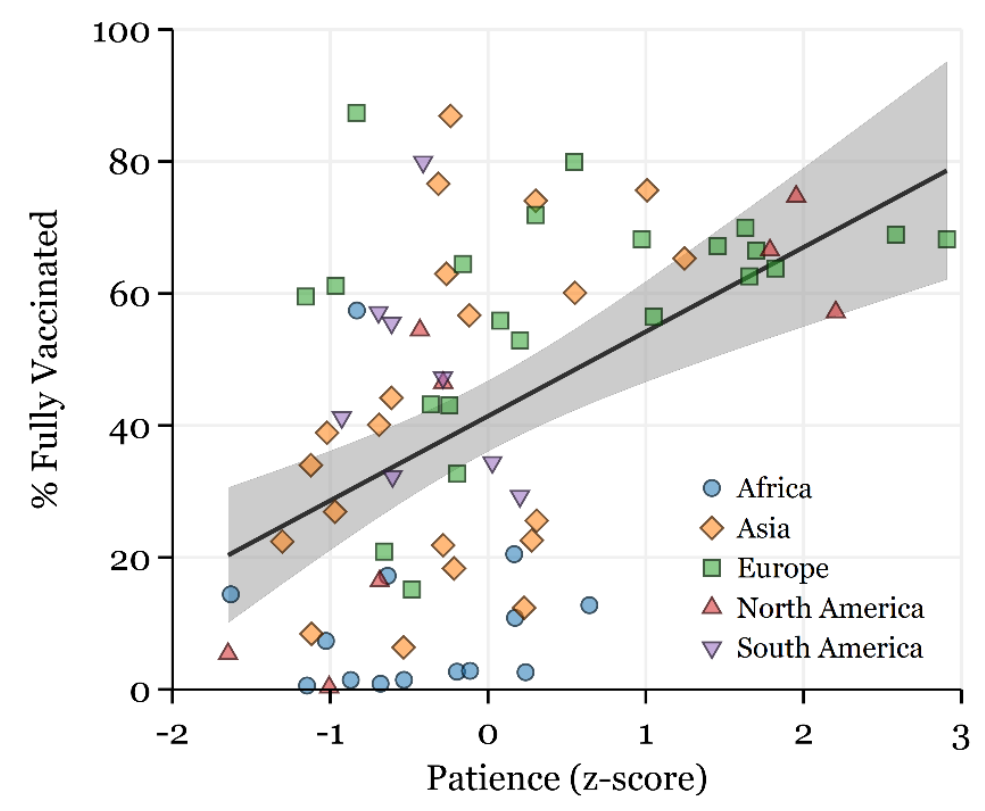

Figure C1. Global variation in vaccination rates and patience: \% fully vaccinated as an alternate outcome. $R^{2}=0.24$ Pearson's $r=0.49 ; p<0.000$. Shaded area represents $95 \%$ CIs.
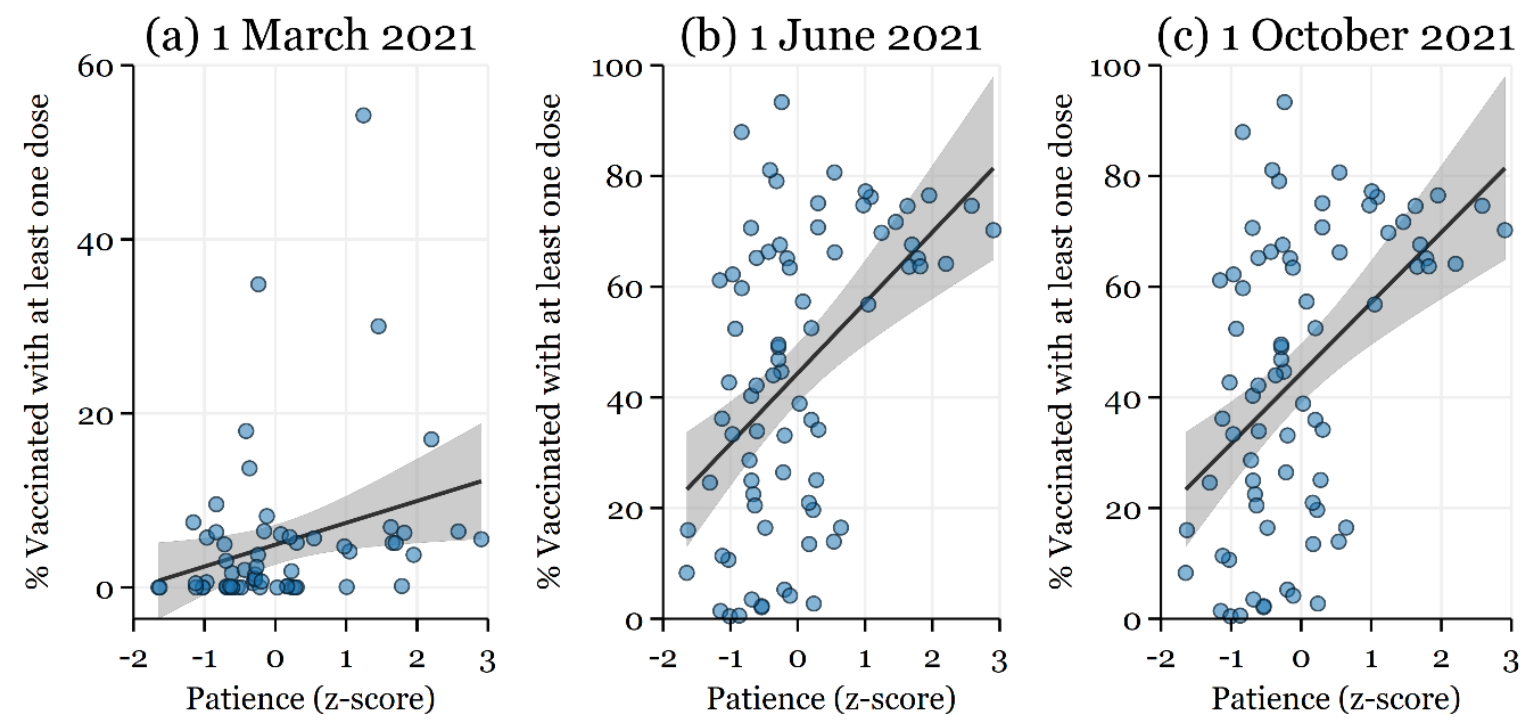

Figure C2. Global variation in vaccination rates and patience at the conclusion of the first, second, and third quarters of 2021. Shaded area represents 95\% CIs. 


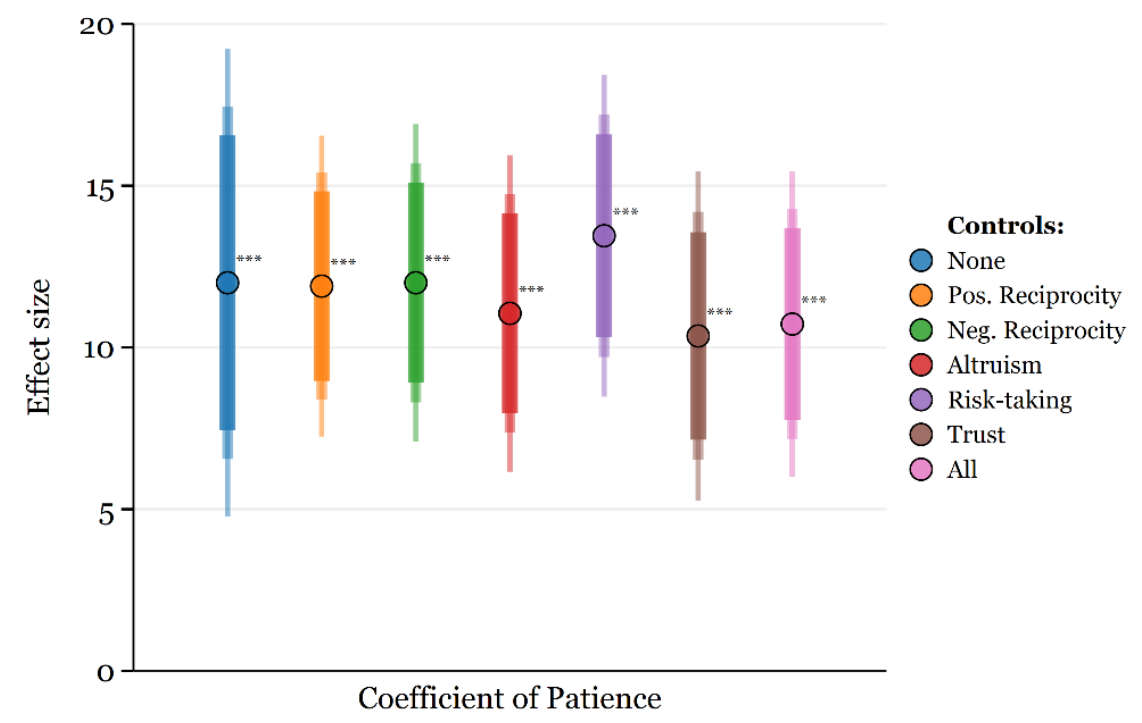

Figure C3. Study 1a: Coefficient of patience conditional on risk and social preferences. Error bars represent $99 \%, 95 \%$, and $90 \%$ CIs, respectively. $* * * \mathrm{p}<0.01$.

Table C1. Study 1a: Partial $R^{2}$ of patience conditional on risk and social preferences.

\begin{tabular}{lc}
\hline Controls & Partial $\mathbf{R}^{\mathbf{2}}$ \\
\hline None & 0.21 \\
Positive Reciprocity & 0.22 \\
Negative Reciprocity & 0.21 \\
Altruism & 0.18 \\
Risk-taking & 0.28 \\
Trust & 0.17 \\
All & 0.21 \\
\hline
\end{tabular}


Table C2. Study 1a: Accounting for the full set of covariates

Dep.Var.: \% Vaccinated with at least one dose

(1)

(2)

All Countries Exclude Vaccine Mandate Countries

\begin{tabular}{|c|c|c|}
\hline \multirow[t]{2}{*}{ Patience } & $4.976^{* *}$ & $6.609 * *$ \\
\hline & {$[2.444]$} & {$[2.651]$} \\
\hline \multirow[t]{2}{*}{ Positive reciprocity } & 3.206 & 3.474 \\
\hline & [3.022] & [3.224] \\
\hline \multirow[t]{2}{*}{ Negative reciprocity } & -1.735 & -0.575 \\
\hline & {$[1.627]$} & {$[1.738]$} \\
\hline \multirow[t]{2}{*}{ Altruism } & -2.995 & -4.369 \\
\hline & [3.143] & [3.099] \\
\hline \multirow[t]{2}{*}{ Risk-taking } & -1.898 & -2.516 \\
\hline & {$[2.315]$} & [2.641] \\
\hline \multirow[t]{2}{*}{ Trust } & -2.557 & -1.934 \\
\hline & [2.012] & [2.155] \\
\hline \multirow[t]{2}{*}{$\ln ($ GDP per capita $)$} & $9.884 * *$ & $9.930 * *$ \\
\hline & {$[4.197]$} & {$[4.270]$} \\
\hline \multirow[t]{2}{*}{$\ln$ (Population density) } & 0.995 & 0.014 \\
\hline & [1.340] & [1.653] \\
\hline \multirow[t]{2}{*}{$\ln ($ COVID-19 cases per capita) } & 1.777 & $2.348^{*}$ \\
\hline & {$[1.220]$} & [1.325] \\
\hline \multirow[t]{2}{*}{ Democracy index } & -0.003 & -0.044 \\
\hline & {$[0.377]$} & {$[0.446]$} \\
\hline \multirow[t]{2}{*}{ Years of Schooling } & $-2.078^{*}$ & $-2.607^{* *}$ \\
\hline & [1.149] & {$[1.230]$} \\
\hline \multirow[t]{2}{*}{ Optimism } & -2.004 & -3.023 \\
\hline & {$[2.686]$} & {$[2.915]$} \\
\hline \multirow[t]{2}{*}{ Hospital beds per thousand } & $-2.775^{* * *}$ & $-2.776^{* * *}$ \\
\hline & {$[0.905]$} & {$[1.017]$} \\
\hline \multirow[t]{2}{*}{ Days w/ universal vaccination } & $0.062 * * *$ & $0.062^{* *}$ \\
\hline & {$[0.021]$} & {$[0.023]$} \\
\hline \multirow[t]{2}{*}{ Median age } & $2.616^{* * *}$ & $2.536 * * *$ \\
\hline & {$[0.632]$} & {$[0.667]$} \\
\hline \multirow[t]{2}{*}{ Experience with MERS or SARS } & 10.207 & $18.741^{* *}$ \\
\hline & {$[7.226]$} & {$[7.911]$} \\
\hline Observations & 71 & 64 \\
\hline R-squared & 0.82 & 0.82 \\
\hline
\end{tabular}

Notes. Heteroskedasticty-robust standard errors in brackets. A constant term and a full set of continent dummies is included in all specifications. ${ }^{* * *} \mathrm{p}<0.01,{ }^{* *} \mathrm{p}<0.05,{ }^{*} \mathrm{p}<0.1$. 


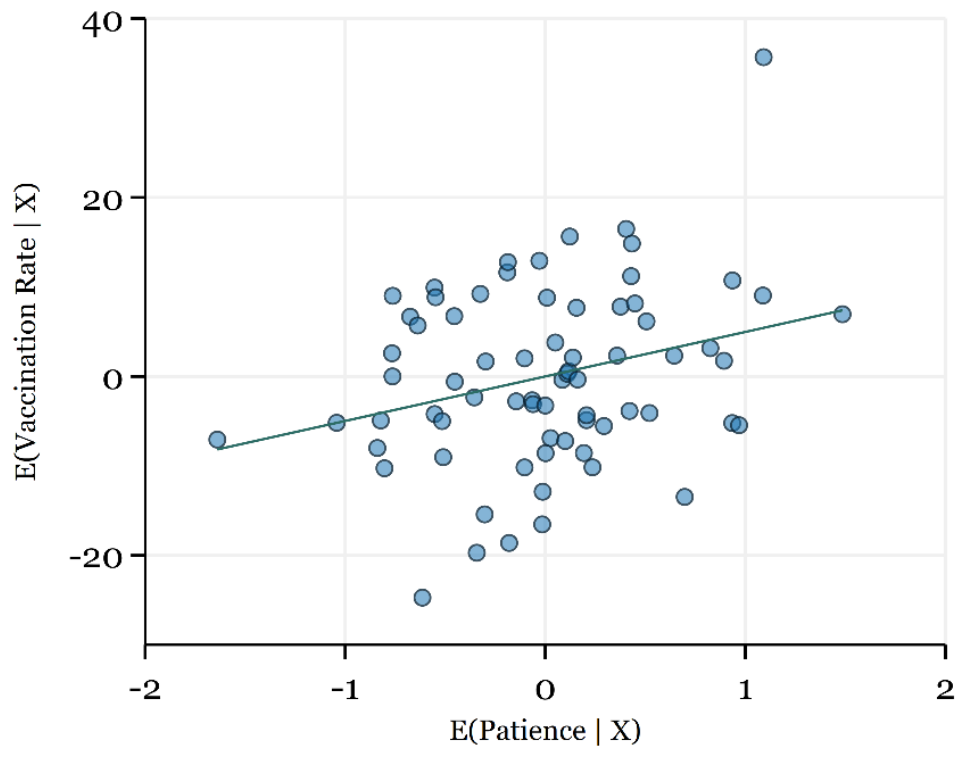

coef $=4.98$, (robust) $\mathrm{se}=2.44, \mathrm{t}=2.04$

Figure C4. Study 1a: Conditional correlation between patience and vaccination. See Table C2 for full regression results.

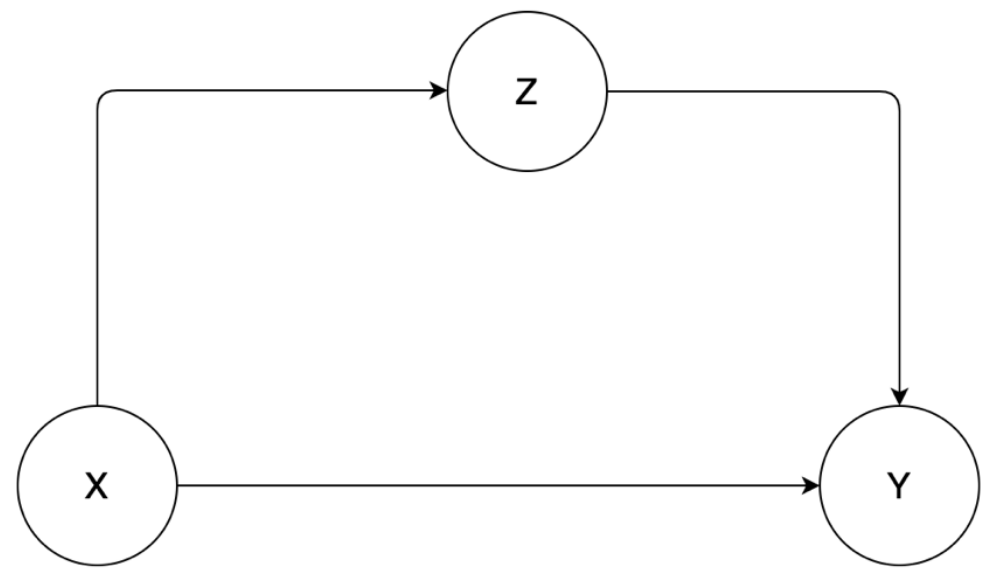

Figure C5. Bad control example: $\mathrm{Z}$ is a bad control, in a model of the form $\mathrm{Y}=a+b \mathrm{X}+u$, if $\mathrm{Z}$ affects $\mathrm{Y}$ and is also an outcome of $\mathrm{X}$, thus causing a downward bias in $\mathrm{b}$, the coefficient of $\mathrm{X}$. 


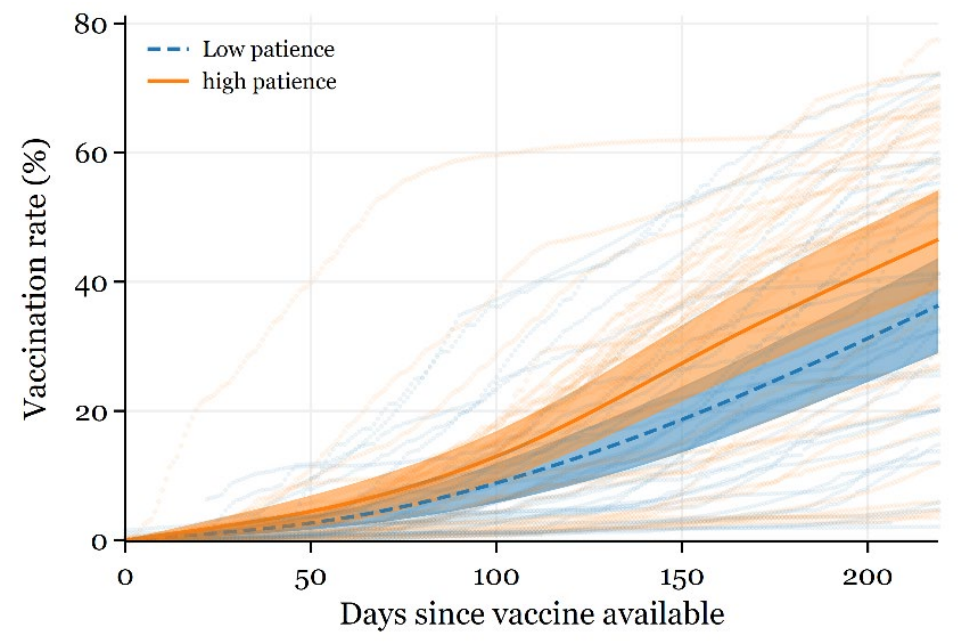

Figure C6. Cumulative vaccination rate. Smoothed lines show the average cumulative vaccination rate of countries with above- (orange) and below-median (blue) patience. Markers represent individual country. Shaded area represents 95\% CIs.

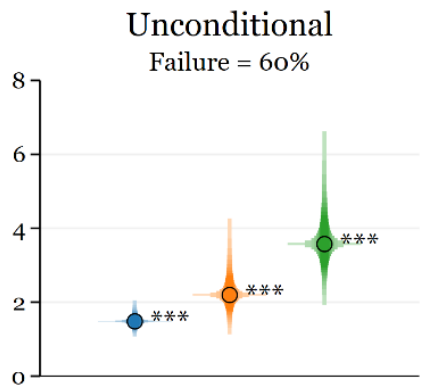

Conditional

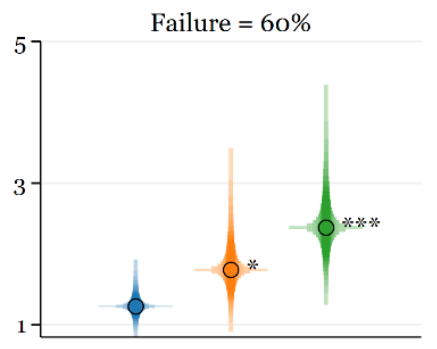

Entry:

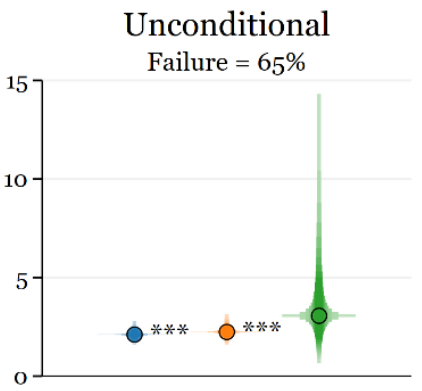

Conditional

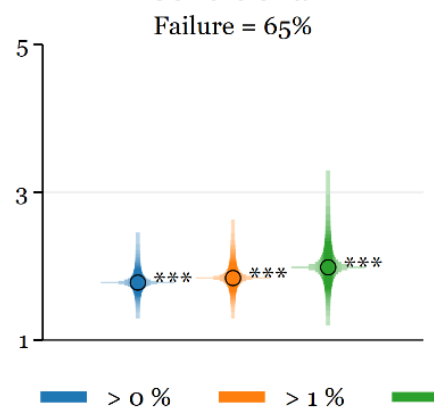

Unconditional

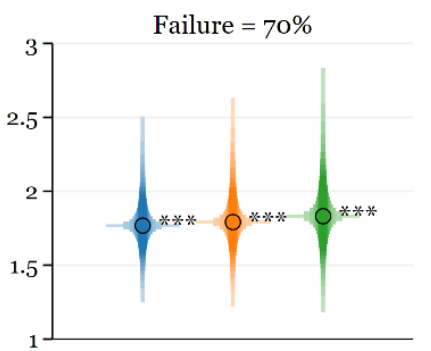

Conditional

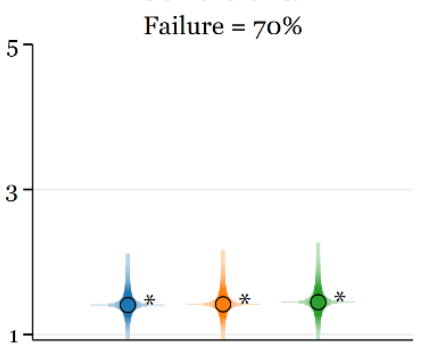

Figure C7. Hazard ratios into vaccination threshold of $60 \%, 65 \%$, and $70 \%$, with time at risk beginning from first vaccination, $5 \%$ vaccinated, and $10 \%$ vaccinated. $* * *$, **, and $*$ denote significance at the 1, 5, and 10\% levels respectively. 